\title{
PENGARUH MOTIVASI KERJA DAN DISIPLIN KERJA TERHADAP KINERJA KARYAWAN PADA PT INDOMARCO PRISMATAMA CABANG BOGOR 2
}

\author{
${ }^{1}$ Melly Safitri, ${ }^{2 *}$ Gojali Supiandi \\ Universitas Pamulang, Tangerang, Banten, Indonesia \\ *dosen01851@unpam.ac.id
}

\begin{abstract}
Abstrak
Penelitian ini bertujuan untuk mengetahui seberapa besar pengaruh motivasi kerja, disiplin kerja terhadap kinerja karyawan pada PT Indomarco Prismatama Cabang Bogor 2 dan yang menjadi objek dalam penelitian ini adalah karyawan pada PT Indomarco Prismatama Cabang Bogor 2. Metode yang digunakan adalah metode deskriptif kuantitatif. Data penelitian dikumpulkan dengan motede penyebaran kuesioner, pengambilan sampel menggunakan sampel jenuh sebanyak 80 responden. Analisis data yang digunakan yaitu uji validitas, uji reliabilitas, uji asumsi klasik, regresi linier sederhana, koefisien korelasi, koefisien determinasi, dan uji hipotesis. Hasil penelitian ini terdapat pengaruh yang positif dan signifikan secara simultan antara motivasi kerja dan disiplin kerja terhadap kinerja karyawan PT. Indomarco Prismatama Cabang Bogor 2.

Kata Kunci: Motivasi Kerja, Disiplin Kerja dan Kinerja Karyawan

Abstract

This study aims to determine how much influence work motivation, work discipline on employee performance at PT Indomarco Prismatama Bogor Branch 2 and the object of this research are employees at PT Indomarco Prismatama Bogor Branch 2. The method used is descriptive quantitative method. The research data were collected using questionnaire distribution method, sampling using saturated sample of 80 respondents. The data analysis used was validity test, reliability test, classical assumption test, simple linear regression, correlation coefficient, determination coefficient, and hypothesis testing. The results of this study that there is a positive and significant influence simultaneously between work motivation and work discipline on the performance of employees of PT. Indomarco Prismatama Bogor Branch 2.
\end{abstract}

Keywords: Work Motivation, Work Discipline and Employee Performance

\section{PENDAHULUAN}

Sumber daya manusia sangat penting bagi suatu organisasi atau perusahaan, baik yang bergerak dalam bidang produksi maupun bidang pelayanan jasa. Setiap Organisasi Pemerintah maupun Swasta di tuntut bekerja lebih cepat, efektif dan efisien. Manusia merupakan mahluk ciptaan Tuhan yang paling sempurna di dunia. Manusia memiliki daya pikir, analisa dan kreatifitas untuk merencanakan, mengorganisasikan, meng- aktualisasikan, dan mengontrol segala sesuatu sesuai dengan fungsinya dalam manajemen

Pada perusahaan semua berusaha untuk mencapai tujuan yang di tetapkan oleh manajemen. Tujuan perusahaan mencakup pertumbuhan, laba, produktivitas, kesejahteraan pegawai dan sebagainya. Kinerja pegawai merupakan salah satu faktor indikator penting yang sangat menetukan dalam menjalankan aktivitas perusahaan dalam mencapai tujuan yang diinginkanSemakin banyak karyawan yang mempunyai kinerja tinggi, maka produtivitas perusahaan semakin secara keseluruhan akan meningkat sehingga perusahaan dapat bertahan dalam persaingan global.

Faktor utama penggerak kegiatan ekonomi adalah manusia. Karena manusia merupakan sumber daya yang sangat penting dalam menentukan keberhasilan suatu perusahaan. Oleh sebab itu, manusialah yang mejadi perencana semua ide dan peraturan-peraturan yang ada 
dalam perusahaan serta merupakan tenaga kerja yang menjadi aset bagi perusahaan dalam meningkatkan kinerjanya.

Dalam hal ini motivasi dan disiplin kerja sangat mempengaruhi profesionalisme tenaga kerja yang diharapkan dapat mendorong perusahaan untuk lebih meningkatkan kinerja karyawan sesuai dengan sasaran yang telah direncanakan. Tujuan perusahaan tidak akan tercapai tanpa adanya peran aktif tenaga kerja yang terampil dan disiplin.

Namun mengatur karyawan merupakan hal yang sulit dan kompleks karena mereka mempunyai pikiran, perasaan, status, dan latar belakang yang heterogen. Sehingga tenaga kerja tidak dapat diatur dan dikuasai sepenuhnya seperti mengatur modal dan gedung.
Menurut Hasibuan

(2017:10) "Manajemen sumber daya manusia adalah suatu bidang manajemen yang khusus mempelajari hubungan dan peran manusia dalam organisasi perusahaan".

Dalam hal ini Motivasi karyawan PT.Indomarco Prismatama Cabang Bogor 2 juga berkurang karena sudah beberapa pemberian motivasi seperti family gathering ataupun pelatihan yang bersifat untuk meningkatkan motivasi dan menambah ilmu bagi karyawan, namun yang terjadi adalah masih terdapat gejala seperti penurunan motivasi, gairah, dan semangat kerja karyawan PT. Indomarco Prismatama Cabang bogor 2. Hal tersebut mengakibatkatkan beberapa unit yang dibutuhkan tidak tercapai dengan baik, kondisi tersebut ditunjukan pada tabel berikut ini:

Tabel 1 Pengukuran Pencapaian

\begin{tabular}{|c|c|c|c|c|}
\hline \multirow{2}{*}{ No } & \multirow{2}{*}{ Tahun } & \multicolumn{2}{|c|}{ Jumlah Pencapaian Pengukuran Unit } & \multirow{2}{*}{ Presentase (\%) } \\
\cline { 3 - 4 } & & Unit yang dibutuhkan & Terealisasi & \\
\hline 1 & 2017 & 260 & 170 & $65,38 \%$ \\
\hline 2 & 2018 & 280 & 190 & $67,85 \%$ \\
\hline 3 & 2019 & 240 & 150 & $62,05 \%$ \\
\hline
\end{tabular}

Sumber : PT. Indomarco Prismatama Cabang Bogor 2

Dari data diatas dapat ditemukan bahwa kinerja karyawan PT. Indomarco Prismatama Cabang Bogor 2 berada pada kondisi yang masih terkoreksi. Dan menunjukan pada bulan Oktober hanya mencapai $65,38 \%$, Bulan November hanya mencapai 67,85\% dan Bulan Desember hanya mencapai $62,05 \%$. Kunci sukses dari tercapainya tujuan perusahaan terletak pada pengelolaan Sumber Daya Manusia yang baik dan benar. Manajer yang bijaksana harus dapat menjaga komunikasi dengan para karyawannya, sehingga semua informasi yang disampaikan dapat diterima untuk dilaksanakan dengan baik dan benar. Dampak yang ditimbulkan tentunya karyawan akan merasa nyaman bekerja diperusahaan yang dipimpinnya.

Suatu organisasi atau lembaga harus mampu mengelola sumber daya manusia yang ada, karena aset utama yang besar pengaruhnya terhadap kemajuan organisasi. Dan Manajemen merupakan salah alat yang digunakan untuk mencapai tujuan yang diinginkan perusahaan dimana proses pengaturan unsur-unsur manajemen yang terdiri dari man, money, method, materials, machines, dan market (6M). Dari salah satu unsur tersebut terdapat Man, yang dimaksudkan adalah Sumber Daya Manusia yang ada dalam perusahaan tersebut. Dengan adanya sumber daya manusia yang mumpuni dapat memberikan pengaruh besar bagi perusahaan karena berusaha dalam mengikuti peraturan yang ada, hal ini akan berdampak pada sikap karyawan. Bagaimana mereka mengatur diri mereka sendiri mematuhi peraturan yang diterapkan. Selain motivasi, dalam pelaksanaan tugas sehari-hari kedisiplinan sering menjadi kendala dalam sebuah organisasi, rendahnya kedisiplinan menjadi persoalan yang berulang-ulang terjadi.

Berikut ini ketimpangan yang terjadi dimana disaat perusahaan sedang menggalakkan program kinerja yang berdaya guna namun justru pada perusahaan ini disiplin kerja menunjukan kurang baik sebagaimana mestinya, karena masih ada yang tidak masuk tanpa 
keterangan. Kondisi tersebut ditunjukan pada data tabel berikut ini:

Tabel 2 Data Absensi Kehadiran Karyawan

\begin{tabular}{|c|c|c|c|c|c|c|}
\hline \multirow{2}{*}{ No } & \multirow{2}{*}{ Tahun } & \multirow{2}{*}{ Jumlah Karyawan } & \multicolumn{3}{|c|}{ Absensi } & \multirow{2}{*}{ presentase (\%) ketidakhadiran } \\
\cline { 3 - 6 } & & Alfa & Ijin & Sakit & \multirow{2}{*}{ (\%) } \\
\hline 1 & 2017 & 80 & 40 & 40 & 40 & $15,00 \%$ \\
\hline 2 & 2018 & 80 & 30 & 40 & 40 & $13,75 \%$ \\
\hline 3 & 2019 & 80 & 30 & 50 & 50 & $16,25 \%$ \\
\hline
\end{tabular}

Sumber: PT. Indomarco Prismatama Cabang Bogor 2

Dari data diatas dapat dilihat bahwa perlunya karyawan menegaskan sikap disiplin kerja hal ini dimaksudkan agar dapat meningkatkan kinerja karyawan yang nantinya akan berdampak baik pula bagi kinerja perusahaan. Banyak upaya yang dilakukan perusahaan untuk meningkatkan disiplin kerja karyawannya dari mulai hanya memberikan teguran sampai sanksi, namun masih banyak kendala yang dihadapi perusahaan dalam rangka meningkatkan disiplin kerja karyawan, itu dikarenakan kurang pengawasan oleh atasan, serta kurangnya rasa tanggung jawab karyawan atas pekerjaan.

Kinerja seorang karyawan merupakan hal bersifat individual, karena setiap karyawan mempunyai tingkat kemampuan yang berbeda-beda dalam mengerjakan tugasnya. Pihak manajemen dapat mengukur karyawan atas unjuk kerjanya berdasarkan kinerja dar imasingmasing karyawan.

Dari data diatas dapat ditemukan adanya kinerja karyawan PT. Indomarco Prismatama Cabang Bogor 2 yang masih kurang optimal karena Beberapa penilaian kinerja yang sudah yang ditentukan mendapatkan nilai kriteria yang kurang memuaskan sehingga tidak sesuai dengan keinginan perusahaan dan akibat juga kurangnya moivasi kerja dan juga kurangnya disiplin kerja karyawan.

Berdasarkan hal tersebut, maka dalam penelitian ini penulis mengambil judul Pengaruh Motivasi Kerja dan Disiplin Kerja Terhadap Kinerja Karyawan Pada PT. Indomarco Prismatama Cabang Bogor 2.

\section{TINJAUAN PUSTAKA}

1. Motivasi Kerja

Menurut Hasibuan

(2017:141)

"Motivasi adalah hal yang menyebabkan, menyalurkan, dan mendukung perilaku manusia, supaya mau bekerja giat dan antusias hasil yang optimal".

Dari definisi diatas peneliti dapat menyimpulkan bahwa motivasi dorongan dan semangat kerja dalam diri seseorang yang menjadikan orang tersebut bertindak

2. Disiplin Kerja

Kedisiplinan merupakan fungsi operasional manajemen sumber daya manusia yang terpenting karena semakin baik disiplin karyawan, semakin baik pula kinerja yang dapat dicapai.

Tanpa disiplin yang baik, sulit bagi organisasi untuk mencapai hasil yang optimal.

Menurut singodimedjo dalam Edy Sutrisno (2016:86) mengatakan disiplin adalah sikap kesediaan dan kerelaan seseorang untuk mematuhi dan menaati norma-norma peraturan yang berlaku disekitarnya.

Menurut Hasibuan (2017:193) disiplin adalah fungsi operatif keenam dari manajemen sumber daya manusia. Kedisiplinan merupakan fungsi operatif manajemen sumber daya manusia yang terpenting karena semakin baik disiplin karyawan, semakin tinggi prestasi kerja yang dicapainya. Tanpa disiplin karyawan yang baik, sulit bagi organisasi perusahaan mencapai hasil yang optimal.

Dari berbagai pengertian diatas dapat ditarik kesimpulan bahwa pengertian disiplin kerja merupakan 
suatu kesediaan karyawan untuk mematuhi semua peraturan-peraturan yang ada dalam perusahaan. Disiplin yang baik mencerminkan besarnya rasa tanggung jawab seseorang terhadap tugas-tugas yang diberikan kepadanya. Hal ini mendorong gairah kerja, semangat kerja, dan terwujudnya tujuan perusahaan, karyawan, dan masyarakat

3. Kinerja Pegawai

Menurut Wibowo (2016:18) mengemukakan "Kinerja merupakan hasil pekerjaan yang mempunyai hubungan kuat strategis organisasi, kepuasan kenosumen dan memberikan kontribusi ekonomi". yang ditampilkan sesuai dengan perannya dalam organisasi. Mathis (2016:113) berpendapat "Kinerja adalah apa yang dilakukan atau tidak dilakukan oleh karyawan". Dengan demikian kinerja merupakan proses pencapaian tujuan organisasi dan hasil dari usaha sumber daya manusia itu sendiri dalam sebuah organisasi.

\section{METODE}

Tempat penelitian ini dilakukan pada PT. Indomarco Prismatama Cabang Bogor 2 , yang beralamat. Di Jalan Kp. Nanggewer No 227, Kelurahan Nanggewer Mekar, Kecamatan Cibinong, Kabupaten Bogor.

Waktu penelitian ini dimulai dari usulan penelitian sampai terlaksananya laporan penelitian, yakni dari bulan Januari sampai dengan bulan Agustus 2020 hingga data dan informasi dapat dilengkapi. Waktu tersebut peneliti gunakan mulai dari tahap persiapan hingga pengumpulan data yang berkaitan dengan judul penelitian.

Beberapa hal yang peneliti lakukan yaitu:

1. Mendatangi bagian pimpinan untuk meminta izin guna melakukan penelitian.

2. Mencari data yang diperlukan sebagai bahan pembuatan skripsi ini.

3. Melakukan wawancara langsung dengan karyawan.

4. Memberikan daftar pertanyaan (kuesioner) kepada para karyawan.

5. Mengevaluasi data yang telah diperoleh.
Pada penelitian ini yang menjadi populasinya adalah karyawan pada PT. Indomarco Prismatama Cabang Bogor 2 yang berjumlah 80 orang. Untuk jumlah sampel dalam penelitian ini berjumlah 80 responden. Jadi sampel dalam penelitian ini adalah karyawan di PT. Indomarco Prismatama Cabang Bogor 2 yaitu berjumlah 80 orang.

\section{HASIL DAN PEMBAHASAN}

1. Pembahasan Hasil Penelitian

Pembahasan

deskriptif

dimaksudkan untuk eksplorasi dan klarifikasi mengenai fenomena atau kenyatan sosial, dengan jalan mendeskripsikan sejumlah variabel yang berkenaan dengan masalah yang diteliti. Pembahasan Deskriptif

a. Keadaan atau kriteria obyek yang diteliti berdasar pada variabel Motivasi kerja (X1)

Perkembangan perusahaan menciptakan persaingan yang ketat. Berbagai cara dilakukan agar dapat kinerja perusahaan tercapai dan dapat dipertahankan. Salah satu strategi yang dipakai perusahaan agar kinerja tercapai dan dapat dipertahankan adalah dengan adanya penerapan motivasi kerja yang baik dari karyawan.

Keadaan atau kriteria secara keseluruhan untuk kuisioner variabel motivasi kerja (X1) diperoleh rata-rata score 4,24 dengan kriteria sangat baik. Dari keseluruhan pernyatan di atas, yang mendapatkan ratting score paling rendah adalah pernyatan (Perusahaan mengangkat pegawai kontrak menjadi pegawai tetap kepada pegawai yang bekerja dengan baik) dimana hanya mendapat score 4,12 .

b. Keadaan atau kriteria obyek yang diteliti berdasar pada variabel disiplin kerja (X2)

Agar kinerja perusahaan dapat tercapai dan dipertahankan. Salah satunya yaitu dengan adanya disiplin yang baik dari karyawan. 
Keadaan atau kriteria secara keseluruhan untuk kuisioner variabel disiplin kerja $(\mathrm{X} 2)$ diperoleh rata-rata score 4,02 dengan kriteria baik. Dari keseluruhan pernyatan di atas, yang mendapatkan ratting score paling rendah adalah pernyatan (Apabila ada pekerjaan tambahan dapat dikerjakan tepat waktu.) dimana hanya mendapat score 3,88

c. Keadaan atau kriteria obyek yang diteliti berdasar pada variabel kinerja (Y)

Perusahaan dituntut untuk memenuhi target kinerja agar tercapai, sehingga perusahaan harus jeli dalam melihat proses dalam produksi.

Keadaan atau kriteria secara keseluruhan untuk kuisioner variabel kinerja (Y) diperoleh rata-rata score 3,99 dengan kriteria baik. Dari keseluruhan pernyatan di atas, yang mendapatkan ratting score paling rendah adalah pernyatan (saya mudah menjalankan dengan baik tanggung jawab yang diberikan oleh perusahan) dimana hanya mendapatkan score 3,21.

2. Pembahasan Verifikatif (Kuantitatif)

Pembahasan verifikatif

(kuantitatif) dimaksudkan untuk membahas perihal pengaruh dan signifikasinya, serta pembahasan keterkaitan teori yang mendukung yang diselaraskan dengan hasil pengolahan data.

a. Pengaruh Motivasi kerja

Terhadap Kinerja $(\mathrm{Y})$

Berdasarkan hasil analisis, diperoleh nilai persamaan regresi $\mathrm{Y}$ $=12.903+0,748 X 1$. Koefisien korelasi sebesar 0,526 artinya kedua variabel memiliki tingkat hubungan yang sedang. Nilai determinasi atau kontribusi pengaruh motivasi kerja (X1) terhadap kinerja (Y) adalah sebesar 0,276 atau $27,6 \%$ sedangkan sisanya sebesar $72,4 \%$ dipengaruhi oleh faktor lain.Uji hipotesis diperoleh nilai $\mathrm{t}$ hitung $>\mathrm{t}$ tabel $(5.460$
$>$ 1.664), hal ini diperkuat dengan probability significancy $0,000<0,05$, Dengan demikian maka H0 ditolak dan $\mathrm{H} 1$ diterima, hal ini menunjukkan bahwa terdapat pengaruh yang signifikan secara parsial antara motivasi kerja terhadap kinerja pada PT. Indomarco Prismatama Cabang Bogor 2

b. Pengaruh Disiplin kerja Terhadap Kinerja (Y)

Berdasarkan hasil analisis, diperoleh nilai persamaan regresi $\mathrm{Y}=$ $12.175+0,613 X 2$. Koefisien korelasi sebesar 0,633 artinya kedua variabel memiliki tingkat hubungan yang kuat. Nilai determinasi atau kontribusi pengaruh disiplin kerja (X2) terhadap kinerja (Y) adalah sebesar 0.401 atau $40,1 \%$ sedangkan sisanya sebesar $59,9 \%$ dipengaruhi oleh faktor lain.Uji hipotesis diperoleh nilai thitung $<\mathrm{t}$ tabel $(7.220$ $<1,664)$. Dengan demikian maka H0 ditolak dan H1 diterima, hal ini menunjukkan bahwa terdapat pengaruh yang signifikan secara parsial antara disiplin kerja terhadap kinerja pada PT. Indomarco Prismatama Cabang Bogor 2.

c. Pengaruh Motivasi kerja (X1) dan Disiplin kerja (X2) Terhadap Kinerja (Y)

Berdasarkan hasil penelitian menunjukan bahwa motivasi kerja (X1) dan disiplin kerja (X2) berpengaruh positif terhadap kinerja (Y) dengan diperoleh persamaan regresi $Y=8.780+0,295 X 1+0,485 X 2$. Nilai koefisien korelasi atau tingkat pengaruh antara variabel bebas dengan terikat diperoleh sebesar 0,653 artinya ketiga variabel memiliki tingkat hubungan yang kuat. Nilai determinasi atau kontribusi pengaruh secara simultan adalah sebesar 0,426 atau $42,6 \%$ sedangkan sisanya sebesar $57,4 \%$ dipengaruhi oleh faktor lain.Uji hipotesis diperoleh nilai $\mathrm{F}$ hitung $>\mathrm{F}$ tabel $(28.607>2,720)$, hal ini diperkuat dengan probability significancy 0,000 
$<0,05$, Dengan demikian maka H0 ditolak dan $\mathrm{H} 1$ diterima, artinya terdapat pengaruh yang signifikan secara simultan antara motivasi kerja dan disiplin kerja terhadap kinerja pada PT. Indomarco Prismatama Cabang Bogor 2.

\section{KESIMPULAN}

Berdasarkan hasil analisis, diperoleh nilai persamaan regresi $Y=12.903+0,748 X_{1}$. Koefisien korelasi sebesar 0,526 artinya kedua variabel memiliki tingkat hubungan yang sedang. Nilai determinasi atau kontribusi pengaruh motivasi kerja $\left(X_{1}\right)$ terhadap kinerja $(\mathrm{Y})$ adalah sebesar 0,276 atau $27,6 \%$ sedangkan sisanya sebesar $72,4 \%$ dipengaruhi oleh faktor lain.Uji hipotesis diperoleh nilai $\mathrm{t}$ hitung $>\mathrm{t}$ tabel $(5.460>1.664)$, hal ini diperkuat dengan probability significancy $0,000<0,05$, Dengan demikian maka $\mathrm{H}_{0}$ ditolak dan $\mathrm{H}_{1}$ diterima, hal ini menunjukkan bahwa terdapat pengaruh yang signifikan secara parsial antara motivasi kerja terhadap kinerja pada PT. Indomarco Prismatama Cabang Bogor 2.

Berdasarkan hasil analisis, diperoleh nilai persamaan regresi $Y=12.175+0,613 X_{2}$. Koefisien korelasi sebesar 0,633 artinya kedua variabel memiliki tingkat hubungan yang kuat. Nilai determinasi atau kontribusi pengaruh disiplin kerja $\left(X_{2}\right)$ terhadap kinerja $(\mathrm{Y})$ adalah sebesar 0.401 atau $40,1 \%$ sedangkan sisanya sebesar $59,9 \%$ dipengaruhi oleh faktor lain.Uji hipotesis diperoleh nilai $\mathrm{t}$ hitung $>\mathrm{t}$ tabel $(7.220>1,664)$. Dengan demikian maka $\mathrm{H}_{0}$ ditolak dan $\mathrm{H}_{2}$ diterima, hal ini menunjukkan bahwa terdapat pengaruh yang signifikan secara parsial antara disiplin kerja terhadap kinerja pada PT. Indomarco Prismatama Cabang Bogor 2.

Berdasarkan hasil penelitian menunjukan bahwa motivasi kerja $\left(X_{1}\right)$ dan disiplin kerja $\left(X_{2}\right)$ berpengaruh positif terhadap kinerja $(\mathrm{Y})$ dengan diperoleh persamaan regresi $\mathrm{Y}=8.780+0,295 \mathrm{X}_{1}+0$, $485 \mathrm{X}_{2}$. Nilai koefisien korelasi atau tingkat pengaruh antara variabel bebas dengan terikat diperoleh sebesar 0,653 artinya ketiga variabel memiliki tingkat hubungan yang kuat. Nilai determinasi atau kontribusi pengaruh secara simultan adalah sebesar 0,426 atau $42,6 \%$ sedangkan sisanya sebesar $57,4 \%$ dipengaruhi oleh faktor lain.Uji hipotesis diperoleh nilai $\mathrm{F}$ hitung $>$ F tabel $(28.607>2,720)$, hal ini diperkuat dengan probability significancy $0,000<0,05$, Dengan demikian maka $\mathrm{H}_{0}$ ditolak dan $\mathrm{H}_{3}$ diterima, artinya terdapat pengaruh yang signifikan secara simultan antara motivasi kerja dan disiplin kerja terhadap kinerja pada PT. Indomarco Prismatama Cabang Bogor 2.

\section{DAFTAR PUSTAKA}

Afandi, P. (2018). Manajemen Sumber Daya Manusia (Teori, Konsep dan Indikator). Riau: Zanafa Publishing.

Affandi, A. (2020). Optimization of MSMEs Empowerment in Facing Competition in the Global Market during the COVID-19 Pandemic Time. Systematic Reviews in Pharmacy, 11(11), 1506-1515.

AM, E. N., Affandi, A., Udobong, A., \& Sarwani, S. (2020). Implementation of Human Resource Management in the Adaptation Period for New Habits. International Journal of Educational Administration, Management, and Leadership, 19-26.

Arikunto, S. (2016). Prosedur Penelitian Suatu Pendekatan Praktik. Jakarta: Rineka Cipta.

Bintoro dan Daryanto. (2017). Manajemen Penilaian Kinerja Karyawan. Yokyakarta: Penerbit Grava Media

Edy, S. (2016). Manajemen Sumber Daya Manusia. Cetakan ke-8. Jakarta: Prenada Media Group

Ghozali, I dan Ratmono, D. (2017). Analisis Multivariat dan Ekonometrika dengan Eviews 10. Badan Penerbit Universitas Diponegoro: Semarang.

Hasibuan, M.S.P. (2016). Manajemen Sumber Daya Manusia. Edisi Revisi. Jakarta: Penerbit PT Bumi Aksara.

Hasibuan, M.S.P. (2017). Manajemen Sumber Daya Manusia. Edisi Revisi. Jakarta: Bumi Aksara. 
Hidayat, D., Prabowo, B., \& Anwar, S. (2020). Organizational Leadership and Conflict in Human Resource Management Review. Solid State Technology, 63(6), 1372-1381.

Kembara, M. D., Hanny, R., Gantina, N., Kusumawati, I., Budimansyah, D., Sunarsi, D., \& Khoiri, A. (2020). Scientific Literacy Profile Of Student Teachers On Science For All Context. Solid State Technology, 63(6), 58445856.

Mangkunegara, A.P. (2017). Manajemen Sumber Daya Manusia Perusahaan. PT. Remaja Rosdakarya. Bandung.

Pabundu, T. (2017). Budaya Organisasi dan Peningkatan Kinerja Perusahaan, cetakan ke-3. Jakarta: PT. Bumi Aksara.

Pawar, A., Sudan, K., Satini, S., \& Sunarsi, D. (2020). Organizational Servant Leadership: A Systematic Literature Review for Implications in Business. International Journal of Educational Administration, Management, and Leadership, 1(2), 63-76. Retrieved from

https://harpressid.com/index.php/I JEAMaL/article/view/8

Prasada, D., Sunarsi, D., \& Teriyan, A. (2020). Pengaruh Etos Kerja Dan Kompensasi Terhadap Komitmen Organisasi Pada DHL Logistic Di Jakarta. JENIUS (Jurnal Ilmiah Manajemen Sumber Daya Manusia), $4(1), 51-60$.

Roswendi, A. S., \& Sunarsi, D. (2020). Dinamika dan Perkembangan Hypnotherapy Dalam Perspektif Interdisipliner. Cilegon: Runzune Sapta Konsultan

Rozi, A., \& Sunarsi, D. (2020). The Influence of Motivation and Work Experience on Employee Performance at PT. Yamaha Saka Motor in South Tangerang. Jurnal Office, 5(2), 65-74.

Sarwani, S., Akbar, I. R., Handoko, A. L., \& Ilham, D. (2020). Pengaruh Pelatihan dan Motivasi terhadap Produktivitas Kerja Karyawan pada PT. Lion Mentari Airlines Bandara Internasional Soekarno Hatta Cengkareng. Jurnal Ilmu Komputer dan Bisnis, 11(2a), 91-100

Sofyan, S., Prasada, D., \& Akbar, I. R. (2020). Pengaruh Motivasi, Lingkungan Kerja dan Kepuasan Kerja Terhadap Kinerja Guru SMP/MTs Muhammadiyah Cabang Sawangan. Jurnal Ilmu Komputer dan Bisnis, 11(2a), 33-44.

Sugiyono. (2017). Metode Penelitian Kuantitatif, Kualitatif, dan R\&D. Bandung: Alfabeta, CV

Sunarsi, D. (2014). Pengaruh Gaya Kepemimpinan, Disiplin dan Motivasi Terhadap Kinerja (Doctoral dissertation, Tesis. Fakultas Ekonomi Universitas Pamulang).

Sutrisno, S., \& Sunarsi, D. (2019). The Effect of Work Motivation and Discipline on Employee Productivity at PT. Anugerah Agung in Jakarta. Jurnal Ad'ministrare, 6(2), 187-196.

Tun Ganyang. M. (2018). Manajemen sumber Daya Manusia. Cetakan pertama. Bogor: IN MEDIA

Wibowo. 2016. Manajemen Kinerja, Edisi Kelima, PT.Rajagrafindo Persada Jakarta.

Widari, T. (2016). Pengaruh disiplin dan lingkungan kerja terhadap kinerja pegawai (Studi pada Badan Kepegawaian Daerah Daerah Istimewa Yogyakarta) Manajemen Fakultas Ekonomi Universitas Negeri Yogyakarta 2016.

Yuangga, K. D., Jasmani, J., \& Sunarsi, D. (2017). The Influence of Technology Determinism and Technology Literacy on Student Learning Outcomes (On MA Daarul Hikmah Pamulang). PINISI Discretion Review, 1(1), 23-30. 